\title{
Erratum to acute exacerbation of interstitial lung diseases secondary to systemic rheumatic diseases: a prospective study and review of the literature
}

\begin{abstract}
Andreina Manfredi ${ }^{1}$, Marco Sebastiani ${ }^{1}$, Stefania Cerri ${ }^{2}$, Caterina Vacchi ${ }^{1}$, Roberto Tonelli $^{2}$, Giovanni Della Casa ${ }^{3}$, Giulia Cassone ${ }^{4,5}$, Amelia Spinella ${ }^{1}$, Fabrizio Pancaldi ${ }^{6}$, Fabrizio Luppi ${ }^{2}$, Carlo Salvarani ${ }^{1,5}$

${ }^{1}$ Rheumatology Unit, University of Modena and Reggio Emilia, Azienda Ospedaliero-Universitaria Policlinico di Modena, Modena, Italy; ${ }^{2}$ Respiratory Disease Unit, University of Modena and Reggio Emilia, Azienda Ospedaliero-Universitaria Policlinico di Modena, Modena, Italy; ${ }^{3}$ Radiology Unit, Azienda Ospedaliero-Universitaria Policlinico di Modena, Modena, Italy; ${ }^{4}$ Clinical and Experimental Medicine PhD program, University of Modena and Reggio Emilia, Modena, Italy; ${ }^{5}$ Rheumatology Unit, IRCCS Arcispedale Santa Maria Nuova, Azienda Unità Sanitaria Locale-IRCCS di Reggio Emilia, Reggio Emilia, Italy; ${ }^{6}$ Department of Sciences and Methods for Engineering, University of Modena and Reggio Emilia, Reggio Emilia, Italy Correspondence to: Dr. Andreina Manfredi. Rheumatology Unit, Azienda Ospedaliero-Universitaria Policlinico di Modena, Via del Pozzo, 71, 41121, Modena, Italy. Email: andreina.manfredi@gmail.com.
\end{abstract}

doi: $10.21037 /$ jtd-2020-64

View this article at: http://dx.doi.org/10.21037/jtd-2020-64

Erratum to: J Thorac Dis 2019;11:1621-8.

Acute exacerbation of interstitial lung diseases secondary to systemic rheumatic diseases: a prospective study and review of the literature

In the article that appeared on Page 1621-1628, Vol 11, No 4 (April 2019) Issue of the fournal of Thoracic Disease (1), the given and family names of author "Fabrizio Pancaldi" was incorrectly published in the original. The author's name should be corrected as Fabrizio Pancaldi, instead of Pancaldi Fabrizio.

The authors regret the error.

Open Access Statement: This is an Open Access article distributed in accordance with the Creative Commons AttributionNonCommercial-NoDerivs 4.0 International License (CC BY-NC-ND 4.0), which permits the non-commercial replication and distribution of the article with the strict proviso that no changes or edits are made and the original work is properly cited (including links to both the formal publication through the relevant DOI and the license). See: https://creativecommons.org/ licenses/by-nc-nd/4.0/.

\section{References}

1. Manfredi A, Sebastiani M, Cerri S, et al. Acute exacerbation of interstitial lung diseases secondary to systemic rheumatic diseases: a prospective study and review of the literature. J Thorac Dis 2019;11:1621-8.

Cite this article as: Manfredi A, Sebastiani M, Cerri S, Vacchi C, Tonelli R, Della Casa G, Cassone G, Spinella A, Pancaldi F, Luppi F, Salvarani C. Erratum to acute exacerbation of interstitial lung diseases secondary to systemic rheumatic diseases: a prospective study and review of the literature. J Thorac Dis 2020;12(10):6411. doi: 10.21037/jtd-2020-64 